\title{
Enterohepatic Distribution of Carnitine in Developing Piglets: Relation to Glucagon and Insulin
}

\author{
B U. K. LI, ROBERT D. MURRAY, LEO A. HEITLINGER, ANNA M. HUGHES, \\ H. JUHLING MCCLUNG, AND THOMAS M. O'DORISIO
}

Departments of Pediatrics [BU.K.L., R.D.M., L.A.H., A.M.H., H.J.M.] and Medicine [T.M.O.], Ohio State University and Wexner Institute of Pediatric Research, Columbus Children's Hospital, Columbus, Ohio 43205

\begin{abstract}
L-Carnitine plays a crucial role in the perinatal transition from carbohydrate to lipid-derived energy. To examine the potential contribution of assimilated dietary carnitine to the elevated hepatic concentrations in newborns, we measured carnitine concentrations in sow milk, jejunum, and liver, and in vitro jejunal carnitine transport in piglets aged 1-36 d. Hepatic and sow milk total carnitine concentrations peaked soon after birth and declined with age $(p=0.035$ and 0.026 , respectively). Although jejunal total carnitine concentrations remained stable, jejunal carnitine flux was higher at $2 \mathrm{~d}$ of age than in older piglets. To examine the possible signals that regulate hepatic carnitine, portal enteroinsular hormones were measured by RIA. Portal glucagon $(p=0.0006)$, insulin $(p=0.0001)$, and glucagon:insulin ratio $(p=0.037)$ were related to age. Portal glucagon was highest in newborns and during weaning, whereas insulin increased progressively with age; the portal glucagon:insulin ratio, like hepatic carnitine, peaked soon after birth and fell with age. A multiple regression analysis indicated a positive association between glucagon and hepatic carnitine and a negative one between insulin and hepatic carnitine $(R=0.802, p=$ 0.001). An overall pattern of elevated dietary carnitine levels and increased small intestinal absorption and hepatic accumulation of carnitine is noted in early development. The finding of a similar pattern in glucagon-to-insulin ratio suggests that both hormones may participate in the regulation of enterohepatic carnitine distribution in newborns. (Pediatr Res 32: 312-316, 1992)
\end{abstract}

\section{Abbreviations}

PEG, polyethylene glycol

SCAC, short-chain acylcarnitine

ANOVA, analysis of variance

NB, newborn group

$\mathrm{S}$, suckling group

$\mathbf{W}$, weaning group

FW, fully weaned group

L-Carnitine is an essential cofactor for the transfer of longchain acyl-CoA into mitochondria for $\beta$-oxidation (1). Carnitine

Received October 31, 1992; accepted April 9, 1992.

Correspondence and reprint requests: B U.K. Li, M.D., Division of Gastroenterology, Columbus Children's Hospital, 700 Children's Drive, Columbus, OH 43205.

Supported by the Children's Hospital Research Foundation, Columbus Children's Hospital, the Bremer Foundation and Seed Grant Program at Ohio State University, and Sigma Tau, Rome, Italy. plays a critical role in the metabolic transition from carbohydrate to lipid-derived energy $(2,3)$ because hepatic glycogen stores become rapidly depleted and endogenous gluconeogenesis is inadequate in the first $24 \mathrm{~h}$ of life $(4,5)$. As such, carnitine insufficiency has been shown to impair lipid utilization in premature newborns $(6,7)$. The human newborn is especially susceptible to develop carnitine insufficiency because of low levels in premature infants (8), inadequate dietary intake of carnitine (9), and insufficient endogenous synthesis (10).

One marker of the switch from glucose to lipid utilization in the newborn is the increase in hepatic carnitine concentrations compared with the fetus (4). In newborn rats, the 4-fold rise in hepatic carnitine has been shown to coincide with enhanced ketone production. Although the origin of hepatic carnitine in newborns has not been fully established, because endogenous synthesis is limited, dietary sources appear to be important. Human and rat milk carnitine concentrations peaked in the first few days after parturition $(4,11)$. In 5 -d-old rats, the contribution of milk carnitine to heart (41\%) and liver (49\%) carnitine stores was substantial (12). We hypothesized that intestinal assimilation of carnitine in newborns is the means of delivery of dietary carnitine to liver. In the first half of the study, we characterized the concentrations of carnitine in sow milk, jejunum, and liver in newborn piglets and examined jejunal transport of carnitine.

There is evidence that glucagon and insulin act as regulatory signals of hepatic fatty acid oxidation $(2,13)$. Exogenous and endogenous (e.g. ketosis) glucagon and insulin have been shown to mediate the carnitine-facilitated transfer of fat into mitochondria by regulating carnitine palmitoyl-transferase (14) and carnitine-acylcarnitine translocase activities, respectively (15). Hepatic transport of carnitine also appears to be hormonally regulated. Kispal et al. $(16,17)$ found that carnitine uptake was stimulated by either the ketotic stress of fasting $(56 \%)$ or the infusion of exogenous glucagon $(66 \%)$. We hypothesized that glucagon and insulin act as signals in the newborn to regulate hepatic carnitine. In the second half of the study, we measured portal glucagon and insulin concentrations during development to compare the temporal pattern with that of hepatic carnitine.

\section{MATERIALS AND METHODS}

Materials. ${ }^{14} \mathrm{C}$-acetyl-CoA and ${ }^{14} \mathrm{C}$-carnitine were purchased from ICN Biochemicals Inc. (Costa Mesa, CA). ${ }^{3} \mathrm{H}$-carnitine was purchased from Amersham Corp. (Arlington Heights, IL). LCarnitine and D,L-carnitine were gifts from Sigma Tau (Rome, Italy). Unlabeled acetyl-CoA, carnitine acetyltransferase, Nethylmaleimide, Dowex anion exchange resin, reagents and standards for creatinine determination, and all salts and buffers were purchased from Sigma Chemical Co. (St. Louis, MO). Highly polymerized calf thymus DNA, indole, and other mate- 
rials for the DNA assay were also purchased from Sigma Chemical Co.

RIA kits for glucagon containing porcine ${ }^{125}$ I-glucagon were purchased from ICN Biomedicals Inc. The first antiglucagon antibody was rabbit antiporcine antibody, and the second, used to precipitate the antigen-antibody complex, was goat antirabbit antibody. Porcine ${ }^{125}$ I-insulin was purchased from New England Nuclear (Boston, MA). The first antiinsulin antibody, a guinea pig antiporcine, was purchased from Research Products International Corp. (Mt. Prospect, IL). The second goat antiguinea pig antibody was purchased from Linco Research Inc. (St. Louis, MO).

Developmental pattern in enterohepatic and sow milk carnitine. The protocol was approved by the Institutional Animal Care and Use Committee of Columbus Children's Hospital. Three-way cross-bred Landrace-Duroc-Yorkshire pigs were used. For studies of milk carnitine concentrations, milk was obtained from three lactating sows at $1,7,14$, and $21 \mathrm{~d}$ of postpartum. For studies of intestinal and hepatic carnitine and portal glucagon and insulin concentrations, three separate liters of piglets were used. Piglets were studied in four age groups: newborn (1-5 d; $n=5)$, suckling (7-23 d; $n=9$ ), weaning (28-29 d; $n=3$ ), and fully weaned $(35-36 \mathrm{~d} ; n=3)$.

After receiving intramuscular ketamine $10 \mathrm{mg} / \mathrm{kg}$ and xylazine $10 \mathrm{mg} / \mathrm{kg}$, a midline laparotomy was performed. A wedge from the right hepatic lobe was removed and frozen in liquid nitrogen $\left(-200^{\circ} \mathrm{C}\right)$ to avoid deesterification of carnitine esters by hepatic esterases (18). For comparison, fetal hepatic tissue was obtained $5 \mathrm{~d}$ before the estimated date of delivery. The proximal half of the small intestine was removed and placed into iced saline. Sections of jejunum were frozen in liquid nitrogen for later assay. All tissue carnitine concentrations were standardized per mg DNA.

Blood samples were drawn just before the removal of liver tissue. Portal venous samples were obtained because they are more representative of the enterohepatic circulation than of the systemic blood. The samples were placed in EDTA-containing tubes and centrifuged, and plasma was stored at $-20^{\circ} \mathrm{C}$ until assayed.

Intestinal carnitine flux. Because jejunal concentrations do not necessarily reflect movement across the intestine, carnitine transport was measured in jejunal segments from piglets $(n=4-5)$ aged 2-4, 16-17, and $30 \mathrm{~d}$. The mid-jejunal segments, stripped of serosa and longitudinal muscle, were mounted in Ussing chambers (surface area $=1.12 \mathrm{~cm}^{2}$ ). Kreb's buffer was warmed $\left(38^{\circ} \mathrm{C}\right)$, oxygenated $\left(95 \% \mathrm{O}_{2} / 5 \% \mathrm{CO}_{2}\right)$, and circulated in a waterjacketed bubble-life apparatus. To the serosal bath, D-glucose (10 $\mathrm{mM}$ ) was added to increase tissue viability, and to the mucosal side, mannitol (10 mM) was added for osmotic balance. After 20 min of stabilization, the experiment was initiated by adding 200 $\mu \mathrm{M}$ unlabeled carnitine to both sides and $3 \mu \mathrm{Ci}{ }^{3} \mathrm{H}$-carnitine to the mucosal bath alone. Under short-circuited conditions, the mucosal-to-serosal flux was determined by the standard formulas (19) based on the appearance of dpm in $200-\mu \mathrm{L}$ aliquots of serosal fluid removed at $20-$ min intervals over $1 \mathrm{~h}$. To examine the possibility that changes inparacellular permeabiltiy contributed to the increased flux in young piglets, the mucosal-to-serosal movement of ${ }^{14} \mathrm{C}-\mathrm{PEG}$ (molecular weight 4000 ) was examined in three 4-d-old and three 35-d-old piglets as described.

Assays. The sow milk was first defatted by the method of Kerner et ao. (20). Weighed aliquots of hepatic and jejunal tissue were thawed to $4^{\circ} \mathrm{C}$ and homogenized in a Polytron homogenizer on ice before assay. Carnitine was then measured by a modification of the radioenzymatic method of Parvin and Pande (21). As previously described, three carnitine fractions were measured separately: free (unesterified) carnitine, the total carnitine level after alkaline hydrolysis, and the long-chain acyl carnitine esters in the acid insoluble pellet (22). The amount of SCAC was calculated as the difference between the long-chain acylcarnitine fraction and the esterified carnitine (= total - free fraction).
DNA was assayed according to the method of Hubbard et al. (23).

RIA for glucagon and insulin in the plasma samples were performed with PEG precipitation of the reacted antigen-antibody complex followed by gamma scintigraphy (24). The specificity of the ${ }^{125} \mathrm{I}$-glucagon antibody enabled measurement of total immunoreactive glucagon, i.e. the cumulative total of glucogon and enteroglucagon, to be referred to simply as glucagon.

Statistical analysis. The effect of age on the carnitine concentrations and jejunal fluxes was examined by ANOVA on four age groups: newborn (NB: 1-5 d), suckling (S: 7-23 d), weaning (W: $28-29 \mathrm{~d}$ ), and fully weaned (FW: $35-36 \mathrm{~d}$ ) piglets. Agerelated changes in portal hormones were compared by ANOVA with post-hoc tests. Multiple regression analysis, with and without interaction between hormones, was used to relate the changes in glucagon and insulin to those in hepatic carnitine. A $p$ value $<0.05$ was considered significant.

\section{RESULTS}

Sow milk, hepatic and jejunal carnitine concentrations. In sow's milk, total carnitine concentrations were highest the day after parturition $(111 \mathrm{nmol} / \mathrm{mL})$ and fell be two thirds by d $21(41$ $\mathrm{nmol} / \mathrm{mL}$ ) just before weaning, as shown in Figure 1. By ANOVA, the total concentrations were related to postnatal age ( $p$ $=0.026)$, with higher values on $\mathrm{d} 1$ and 7 than at $\mathrm{d} 21(p<$ 0.023 for both comparisons). The postpartum decline in sow milk carnitine was attributable to a fall in free (unesterified) carnitine $(p=0.012)$ : concentrations on $\mathrm{d} 1$ were higher than those on $\mathrm{d} 14$ and 21 ( $p<0.028$ for both).

When hepatic concentrations of total carnitine were measured in fetuses $5 \mathrm{~d}$ before their estimated delivery date, the were low (55 nmol/mg DNA), as shown in Figure 2. Postnatally, hepatic total carnitine was highest in newborns $(187 \mathrm{nmol} / \mathrm{mg}$ DNA) and fell 4-fold after weaning (41 nmol/mg DNA). Post-hoc tests revealed that total carnitine was related to age $(p=0.035)$ with the order of values $\mathrm{NB}>\mathrm{S}>\mathrm{W}>\mathrm{FW}$; significantly higher values were found for $\mathrm{NB}>\mathrm{W}$ and NB $>\mathrm{FW}(p<0.025$ for both). The fall in total carnitine during development was due to a significant decline in the SCAC fraction $(p=0.044)$. The newborn SCAC values were higher than all other ages $(p<0.024$ for each comparison).

In contrast to sow milk and hepatic concentrations, jejunal total carnitine did not display an age-related pattern but remained stable between 31 and $43 \mathrm{nmol} / \mathrm{mg}$ DNA during development (Fig. 3). The carnitine fractions were similar in each age group.

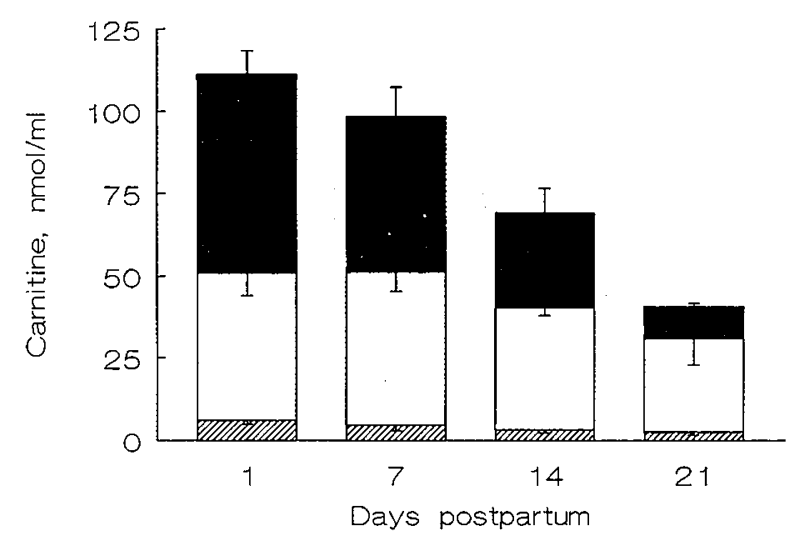

Fig. 1. Sow milk carnitine concentrations during suckling. Individual bars represent the mean \pm SEM of three sows. The total carnitine concentration is represented by the height of the bar, and individual fractions of carnitine are shown as follows: free fraction (unestrified), solid bar; short-chain acylcarnitine, open bar; and long-chain acylcarnitine, diagonal-lined bar. By ANOVA, sow milk total and free carnitine concentrations were related to age ( $p=0.026$ and 0.012 , respectively). 
(5)

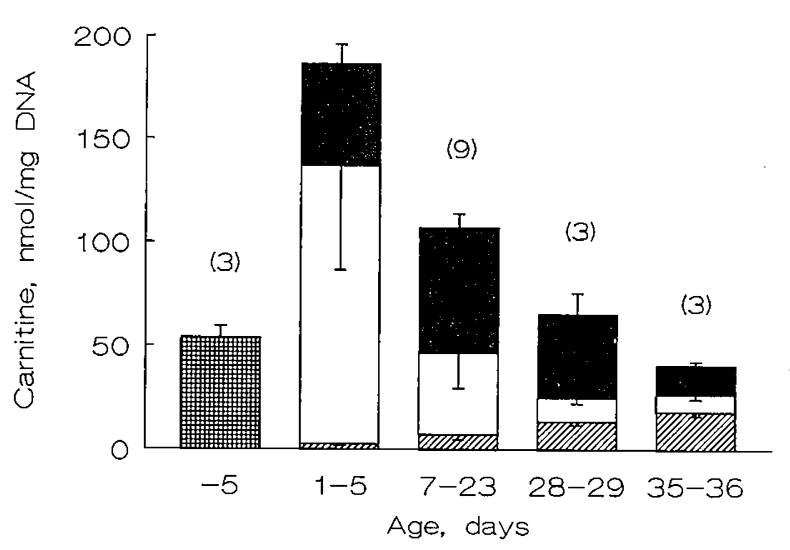

Fig. 2. Hepatic carnitine concentrations during postnatal development. Individual bars represent the mean \pm SEM for three to nine animals (shown in parentheses). The total carnitine concentration is represented by the height of the bar, and individual fractions are shown as follows: free, solid bar; SCAC, open bar; and long-chain acylcarnitine, diagonal-lined bar. The cross-hatched bar represents the total carnitine concentration in fetal piglets. By ANOVA, hepatic total and SCAC concentrations were related to age ( $p=0.035$ and 0.044 , respectively).

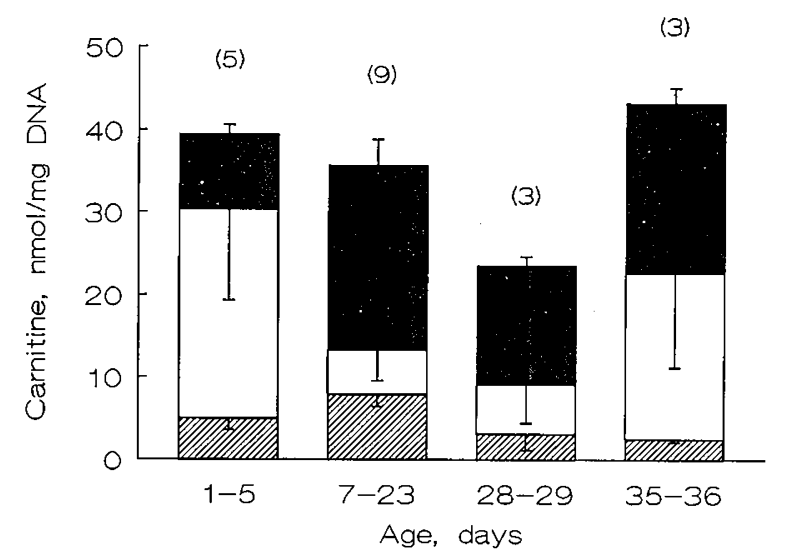

Fig. 3. Jejunal carnitine concentrations during postnatal development. Individual bars represent the mean \pm SEM for three to nine animals (shown in parentheses). Total carnitine concentration is represented by the height of the bar, and individual fractions are shown as follows: free, solid bar; SCAC, open bar; and long-chain acylcarnitine, diagonal-lined bar. No significant relationship of jejunal carnitine concentrations to age was noted.

Jejunal carnitine flux. The unidirectional mucosal-to-serosal flux of carnitine was related to postnatal age $(p<0.001)$, as shown in Figure 4. Rates of flux were higher in newborn than in fully weaned piglets, falling from 97 to $44 \mathrm{nmol} / \mathrm{cm}^{2} / \mathrm{h}(p<$ 0.05 ). When the permeability to PEG 4000 was tested, similar amounts of 1.5 and $1.8 \%$ appeared in the serosal baths of newborn and fully weaned animals, respectively.

Portal glucagon and insulin concentrations and ratio. Portal glucagon concentrations were related to postnatal age $(p=$ 0.0006 ), as shown in Figure 5. The order of concentrations was $\mathrm{W}(779 \mathrm{pg} / \mathrm{mL})>\mathrm{NB}(412 \mathrm{pg} / \mathrm{mL})>\mathrm{S}(287 \mathrm{pg} / \mathrm{mL})>\mathrm{FW}$ $(203 \mathrm{pg} / \mathrm{mL})$. The peak value during weaning was higher than in any other age group $(p<0.004$ for each comparison). One animal with a level of $2490 \mathrm{pg} / \mathrm{mL}$ on d 1 was excluded on the basis of an outlier test (25).

Portal insulin concentrations were also related to postnatal age $(p=0.0001)$, as seen in Figure 6. In contrast to the pattern for glucagon concentrations, portal insulin steadily increased with age $(\mathrm{NB}<\mathrm{S}<\mathrm{W} \approx \mathrm{FW})$ from 2.4 to $15.3 \mu \mathrm{U} / \mathrm{mL}$. The weaning

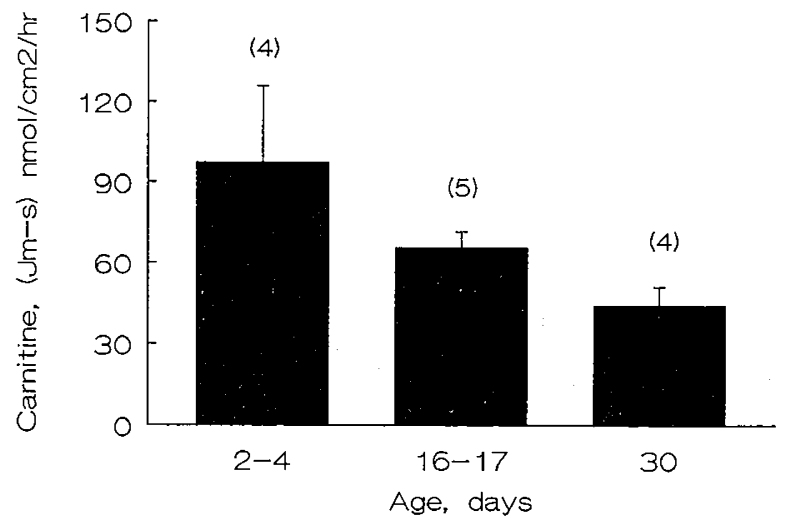

Fig. 4. In vitro jejunal carnitine mucosal-to-serosal fluxes $(\mathrm{Jm}-\mathrm{s})$ at three postnatal ages. Each bar represents the mean \pm SEM of the number of animals indicated in parentheses. By ANOVA, jejunal fluxes were related to age $(p<0.001)$.

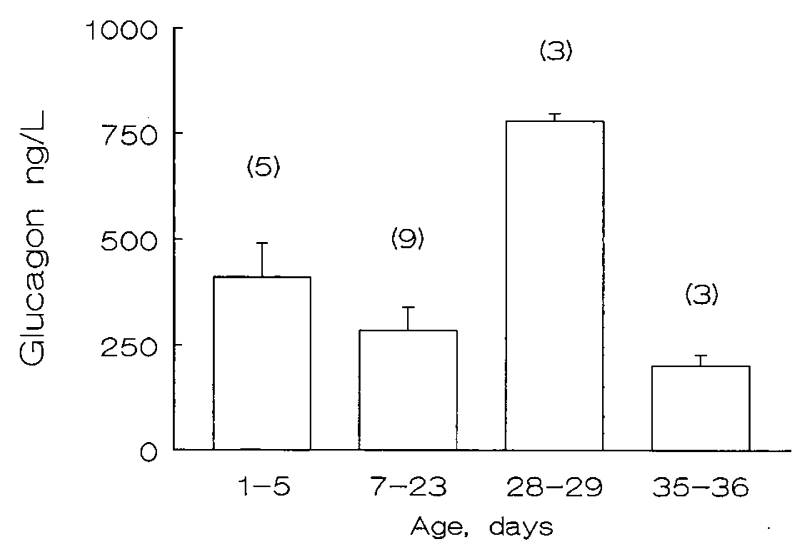

Fig. 5. Portal venous glucagon during postnatal development. Individual bars represent the glucagon concentration (mean \pm SEM) of three to nine animals (shown in parentheses). By ANOVA, portal glucagon concentrations were related to age $(p=0.0006)$.

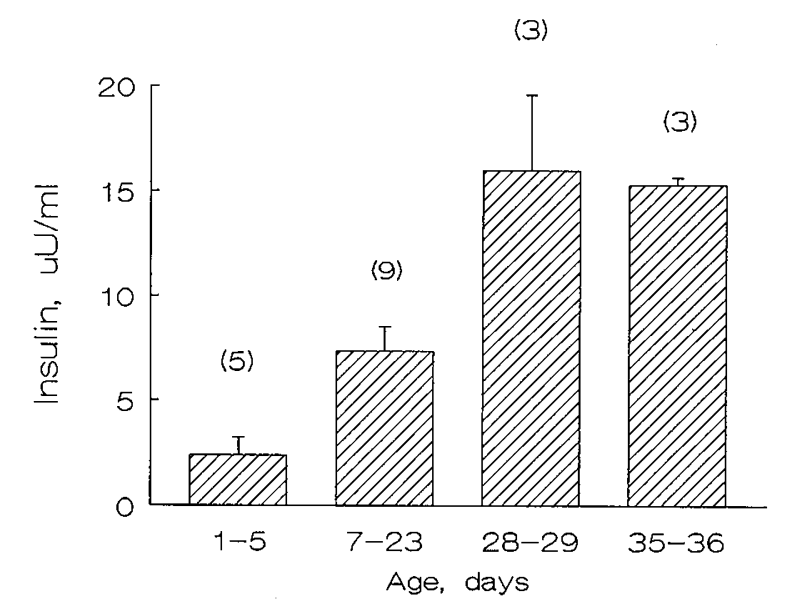

Fig. 6. Portal venous insulin during postnatal development. Individual bars represent the insulin concentration (mean \pm SEM) of three to nine animals (shown in parentheses). By ANOVA, portal insulin concentrations were related to age $(p=0.0001)$.

and postweaned values were higher than those in the newborn and suckling periods ( $p<0.004$ for each comparison).

Portal glucagon:insulin ratios were also related to postnatal age $(p \approx 0.037)$, as shown in Figure 7 . The portal glucagon:insulin ratio declined with age from 295 to $13 \mathrm{ng} / \mathrm{mU}(\mathrm{NB}>\mathrm{S}>\mathrm{W}>$ FW). The ration in newborns was significantly higher than those at all other ages ( $p<0.035$ for each comparison). 


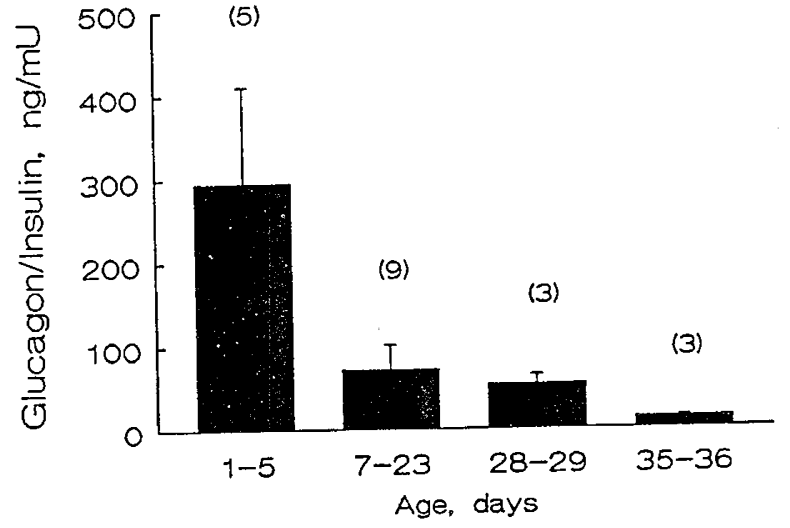

Fig. 7. Portal venous glucagon:insulin ratio during postnatal development. Individual bars represent the glucagon:insulin ratio (mean \pm SEM) of three to nine animals (shown in parentheses). By ANOVA, portal glucagon:insulin ratios were related to age $(p=0.037)$.

The possible relationship between enteroinsular hormones and total hepatic carnitine was examined by multiple regression analysis. Hepatic carnitine was related to portal glucagon and insulin $(R=0.734 ; p=0.001)$. The standard coefficients for glucagon $(\beta=0.431)$ and insulin $(\beta=-0.650)$ were significant, of similar magnitude and in opposite directions. Inclusion of an insulin by glucagon interaction term increased the multiple correlation to $R=0.802(p=0.001)$.

\section{DISCUSSION}

In the first part of the study, we examined the temporal pattern of carnitine distribution among dietary supply, gut, and liver by measuring concentrations in sow's milk, jejunum, and liver. The results showed that sow milk carnitine concentrations and piglet accumulation and transport of carnitine by liver and jejunum, respectively, were highest soon after birth and fell with age. One $\mathrm{d}$ after birth, at a time of heightened need for hepatic carnitine, sow milk carnitine concentrations were highest, as was previously reported in rat and human milk $(4,11)$. The fall in total carnitine was due primarily to changes in the free fraction, the fraction most readily absorbed by small intestine (26).

Immediately after birth, an accumulation of hepatic total carnitine was observed, resulting in an early postnatal peak and subsequent fall similar to that seen previously in rodents (4). The peak in hepatic carnitine soon after birth indicated that the rise was most likely a postnatal rather than an antenatal event. This increase coincides with a greater functional capacity to oxidize fatty acids and produce ketones $(4,27)$. The amount of hepatic carnitine is not rate limiting for fatty acid oxidation. However, the striking increase in carnitine constitutes an indicator, and a possible promoter, of the heightened fatty acid oxidation in newborns $(4,27-29)$. The postnatal fall in carnitine was due to decreasing SCAC esters in piglets, whereas that in rodents was due to a decline in the free fraction (4). Although its significance is unknown, this change in profile may reflect the increased acetyl-CoA and acetylcarnitine production during the initial period of rapid lipid utilization (30).

To accommodate the hepatic accumulation, we hypothesized that intestinal carnitine assimilation must also be enhanced in the newborn at a time of limited carnitine synthesis. Although jejunal carnitine concentrations remained stable from the newborn to fully weaned period, the highest rates of jejunal transport of carnitine were found in newborns compared to suckling and fully weaned animals. The in vitro data have been previously corroborated by in vivo perfusions in which a 3-fold higher rate of carnitine uptake was observed in newborn compared to fully weaned piglets (31). The observed pattern could not be readily explained by gross changes in intestinal permeability as detected by PEG 4000 movement.
It appears that the postnatal adaptation in intestinal assimilation occurs not only for carnitine, a cofactor for lipid utilization, but also for dietary lipids as well. Intestinal trioleate absorption has been demonstrated to proceed at rates that are higher in suckling than in adult rats (32). In addition, porcine jejunal concentrations of fatty acid binding protein, an intracellular transport protein for fatty acids, like hepatic carnitine, peak soon after birth and decline with age (33).

In the second part of the study, we examined possible hormonal signals that could affect hepatic carnitine accumulation in piglets. Because glucagon and insulin are hormones that regulate hepatic $\beta$-oxidation of fatty acids, we postulated that they also might influence hepatic carnitine in the newborn period. Although elevated glucagon concentrations have been observed in newborn lambs (34), dog pups (35), and piglets within $48 \mathrm{~h}$ of birth $(36,37)$, the temporal pattern through weaning had not been previously established in swine.

The early peak in portal glucagon was probably the combined result of three influences: 1) the "glucagon surge", which occurs within $30 \mathrm{~min}$ of birth, attributed to the physiologic consequences of severing the umbilical cord $(34) ; 2$ ) hyperglucagonemia, which begins during the first $24 \mathrm{~h}$ of life, induced by the hypoglycemia resulting from hepatic glycogen depletion $(2,36)$; and 3) a sustained enteroglucagonemia, which persists during the first $3 \mathrm{wk}$ of suckling, a response to enteral feedings (38). Although unexpected, the peak that was identified during weaning probably resulted from two stresses that accompany weaning: the psychologic stress of being removed from the sow and the physiologic stress of fasting before the intake of solid foods becomes well established. Because glucagon is a principal stress hormone, the biphasic peak likely indicates that the perinatal and weaning transitions were both critical for the piglet.

Portal insulin concentrations rose progressively throughout development and peaked during and after weaning, in contrast to the pattern observed for glucagon.

When the portal glucagon:insulin ratio was examined, the pattern paralleled that of hepatic carnitine. This pattern had not been previously established in newborn piglets. When the possibility of a relationship between enteroinsular hormones and hepatic carnitine was explored, multiple regression analysis indicated that a significant correlation existed and included an interaction term (insulin by glucagon). As such, glucagon appeared to have a positive effect and insulin a negative one on hepatic carnitine, and the insulin effect became greater at higher glucagon concentrations. In this model, the high glucagon and low insulin concentrations after birth would lead to maximal hepatic carnitine concentrations. Because the hormonal effects ( $\beta$ weights) were of similar magnitude, at weaning, the stimulatory effect of peak glucagon on hepatic carnitine would be abolished by the concomitant inhibitory effect of peak insulin. These correlations support the concept that both hormones participate in the regulation of hepatic carnitine in newborns.

Several lines of evidence support a relationship between enteroinsular hormones and hepatic carnitine. McGarry and Foster $(4,28)$ have proposed the regulatory role of glucagon and insulin to explain the rise in hepatic carnitine that occurs in other ketogenic conditions such as fasting and diabetes. The newborn milieu shares multiple similarities with those two conditions, including insufficient cellular glucose, heightened fatty acid oxidation and ketogenesis, hyperglucagonemia, hypoinsulinemia, and increased hepatic carnitine concentrations (29). Under experimental conditions, exogenous glucagon increases and insulin attenuates hepatic carnitine concentrations, respectively $(28,29)$. In fact, exogenous glucagon can reproduce the stimulatory effect of fasting on hepatic accumulation of carnitine $(16,17)$.

There are at least two physiologic stimuli that could produce the enterohepatic carnitine response, dietary composition, and metabolic stress. Hepatic carnitine would be required as a cofactor to use the major portion $(>54 \%)$ of sow milk calories composed of lipid. During development, the percentage of fat in sow 
milk increased by $28 \%$, whereas hepatic carnitine levels in piglets decreased by $456 \%$ (39). Thus, the developmental pattern in hepatic carnitine is unlikely to be explained by a change in dietary lipids. Because hepatic carnitine is known to respond acutely to other ketogenic stresses, we speculate that the newborn changes are part of the adaptive and functional response to the lack of glucose availability $(2,5,13)$.

In summary, the enterohepatic distribution of carnitine, i.e. dietary availability of carnitine, its intestinal transport, and hepatic accumulation, is increased immediately after birth. The net effect is a more rapid transfer of dietary carnitine to the hepatic site of heightened lipid utilization. This finding supports the concept that exogenous carnitine contributes to newborn homeostasis. The association between portal glucagon, insulin, and the hepatic carnitine leads us to speculate that hepatic accumulation and possibly jejunal transfer of carnitine are regulated by the metabolic needs of the newborn.

Acknowledgments. The authors thank Phil Bowers, Tony Ailabouni, Priscilla Powers, Gina Siravo-Seagraves, Bela Bhatt, Jill Woods, and Dr. Hugh Harroff for their excellent technical assistance. Drs. Don Mahan and Greg Reinhart supplied the sow milk samples. John Hayes and Sarolyn Tillman contributed expert statistical and secretarial help, respectively.

\section{REFERENCES}

1. Bremer J 1983 Carnitine-metabolism and functions. Physiol Rev 63:14201479

2. Ferre P, Decaux JF, Issad T, Girard J 1986 Changes in energy metabolism during the suckling and weaning period in the newborn. Reprod Nutr Dev 26:619-631

3. Hahn P, Novak M 1985 How important are carnitine and ketones for the newborn infant? Fed Proc 44:2369-2373

4. Robles-Valdes C, McGarry JD, Foster DW 1976 Maternal-fetal carnitine relationships and neonatal ketosis in the rat. J Biol Chem 251:6007-6012

5. Kimura RE, Warshaw JB 1983 Metabolic adaptations of the fetus and newborn. J Pediatr Gastroenterol Nutr 2:S12-S15

6. Helms RA, Whitington PF, Mauer EC, Catarau EM, Christensen ML, Borum PR 1986 Enhanced lipid utilization in infants receiving oral L-carnitine during long-term parenteral nutrition. J Pediatr 109:984-988

7. Penn D, Schmidt-Sommerfield E, Pascu F 1981 Decreased tissue carnitine concentrations in newborn infants receiving total parenteral nutrition. J Pediatr 98:976-978

8. Shenai JP, Borum PR 1984 Tissue carnitine reserves of newborn infants. Pediatr Res 18:679-681

9. Novak M, Weiser PB, Buch M, Hahn P 1979 Acetylcarnitine and free carnitine in body fluids before and after birth. Pediatr Res 13:10-15

10. Rebouche CJ, Engel AG 1980 Tissue distribution of carnitine biosynthetic enzymes in man. Biochim Biophys Acta 630:22-29

11. Sandor A, Pecsuvac K, Kerner J, Alkonyi I 1982 On carnitine content of the human breast milk. Pediatr Res 16:89-91

12. Davis AT 1989 Fractional contributions to total carnitine in the neonatal rat. J Nutr 119:262-267

13. Girard J, Duee PH, Ferre P, Pegorier JP, Escriva F, Decaux JF 1985 Fatty acid oxidation and ketogenesis during developmeng. Reprod Nutr Dev 25:303319

14. Gamble MS, Cook GA 1985 Alteration of the apparent $\mathrm{Ki}$ of carnitine palmitoyltransferase for malonyl-CoA by the diabetic state and reversal by insulin. J Biol Chem 260:9516-9519

15. Parvin R, Pande SV 1979 Enhancement of mitochondrial carnitine and carnitine acylcarnitine translocase-mediated transport of fatty acids into liver mitochondria under ketogenic conditions. J Biol Chem 254:5423-5429

16. Kispal G, Melegh B, Alkonyi I, Sandor A 1987 Enhanced uptake of carnitine by perfused rat liver following starvation. Biochim Biophys Acta 896:96102

17. Kispal G, Melegh B, Sandor A 1987 Effect of insulin and glucagon on the uptake of carnitine by perfused rat liver. Biochim Biophys Acta 929:226228

18. Perason DJ, Tubbs PK 1967 Carnitine and derivatives in rat tissues. Biochem J 105:953-963

19. Schultz SG, Zalusky R 1964 Ion transport in isolated rabbit ileum. I. Shortcircuit current and $\mathrm{Na}^{+}$fluxes. J Gen Physiol 47:567-584

20. Kerner J, Froseth JA, Miller ER, Bieber LL 1984 A study of the acylcarnitine content of sows' colostrum, milk and newborn piglet tissues: demonstration of high amounts of isovalerylcarnitine in colostrum and milk. J Nutr 114:854-861

21. Parvin R, Pande SV 1977 Microdetermination of (-) carnitine and carnitine acetyltransferase activity. Anal Biochem 79:190-201

22. Gudjonsson H, Li BUK, Shug AL, Olsen WA 1985 Studies of carnitine metabolism in relation to intestinal absorption. Am J Physiol 248:G313G319

23. Hubbard RW, Matthew WT, Moulton DW 1972 Factors influencing the determination of DNA with indole. II. Recovery of hydrolyzed DNA from protein precipitates. Anal Biochem 46:461-472

24. Morgan CR, Lazarow A 1963 Immunoassay of insulin: two antibody systemplasma insulin levels in normal, subdiabetic and diabetic rats. Diabetes $12: 115-126$

25. Tietjen GL 1986 The analysis and detection of outliers. In: D'Agostino RB, Stephens MA (eds) Goodness of Fit Techniques. Marcel Dekker, New York, pp 497-522

26. Shaw RD, Li BUK, Hamilton JW, Shug AL, Olsen WA 1983 Carnitine transport in rat small intestine. Am J Physiol 245:G376-G381

27. McGarry JD, Wright PH, Foster DW 1975 Hormonal control of ketogenesis: rapid activation of hepatic ketogenic capacity in fed rats by anti-insulin serum and glucagon. J Clin Invest 55:1202-1209

28. McGarry JD, Foster DQ 1977 Hormonal control of ketogenesis. Arch Intern med 137:495-501

29. McGarry JD, Robles-Valdes C, Foster DW 1975 Role of carnitine in hepatic ketogenesis. Proc Natl Acad Sci USA 72:4385-4388

30. Bieber LL 1988 Carnitine. Annu Rev Biochem 57:261-283

31. Li BUK, Nowicki PT, Hughes AM, Miller CE, Murray RD, Heitlinger LA, McClung HJ 1991 Enhanced intestinal transport of carnitine in newborns: possible role of glucagon. Gastroenterology 100:A530(abstr)

32. Flores CA, Hing SAO, Wells MA, Koldovsky O 1989 Rates of triolein absorption in suckling and adult rats. Am J Physiol 89:G823-G829

33. Reinhart GA, Simmen FA, Mahan DC, Simmen RCM, White ME 1990 Isolation, characterization and developmental expression of pig intestinal fatty acid binding proteins. J Nutr Biochem 1:592-598

34. Grajwer LA, Sperling MA, Sack J, Fisher DA 1977 Possible mechanisms and significance of the neonatal surge in glucagon secretion: studies in newborn lambs. Pediatr Res 11:833-836

35. Ghiglione M, Pascual JM, Rivira A, Calvo G, Valverde I 1985 Plasma glucagon-immunoreactive components in early life in dogs. Horm Metab Res 17:387-390

36. Pegorier JP, Duee PH, Assan R, Peret J, Girard J 1981 Changes in circulating fuels, pancreatic hormones and liver glycogen concentration in fasting or suckling newborn pigs. J Dev Physiol 3:203-217

37. Silver M, Fowden AL, Comline RS, Bloom SR 1986 Pancreatic alpha cell function in the fetal and newborn pig. J Endocrinol 108:137-142

38. Lucas A, Bloom SR, Aynsley-Green A 1980 Development of gut hormone respones to feeding in neonates. Arch Dis Child 55:678-682

39. Pond WG, Houpt KA 1978 Biology of the Pig. Comstock Publishing, San Francisco, pp 185-189 